\title{
Políticas Públicas e Organizações na Educação do Surdo
}

\author{
Edjonas Silvana Lopes ${ }^{l}$; Francimária Sousa Santos Silvana²; Anny Caroline Costa Vieira ${ }^{3}$; Gislene Farias de Oliveira ${ }^{4}$
}

\begin{abstract}
Resumo: Este trabalho pretende refletir sobre as políticas públicas para a educação dos Surdos no Brasil, desde o século XIX quando um decreto imperial fez nascerem os primeiros institutos para o atendimento as pessoas cegas e surdas. Ressaltando ainda a fundação do INES, Instituto Nacional de Educação de Surdos, o qual oferece ensino formal e ensino profissionalizante para surdos. A Língua Brasileira de Sinais - Libras, é conhecida como a língua dos surdos, ela não é apenas gestos e mímicas, mas trata-se e uma combinação sistemática de gestos e mímicas acrescida da expressão facial e movimentos corporais, o que possibilita uma perfeita comunicação dos surdos com outros surdos e de surdos com os ouvintes que compreendem a língua. O bilinguismo é uma proposta educacional para o Surdo, onde possibilita o mesmo estudar e comunicar-se com duas línguas distintas, a Libras e a Língua Portuguesa. Diversas Leis, Decretos e Resoluções foram elaboradas e divulgadas pensando na inclusão de pessoas com deficiência no Brasil, cabe então aos estados e municípios executarem o que foi dito nos textos legais, visando dessa maneira proporcionar uma maior participação efetiva dessas pessoas na sociedade e preparação para o mercado de trabalho.
\end{abstract}

Palavras-chaves: Surdos. Leis. Libras. Bilinguismo.

\section{Public Policies and Organizations in the Education of the Deaf}

\begin{abstract}
This work intends to reflect on public policies for the education of the Deaf in Brazil, since the 19th century when an imperial decree made the first institutes for the care of blind and deaf people born. Also highlighting the founding of INES, the National Institute of Deaf Education, which offers formal education and vocational education for the deaf. The Brazilian Language of Signs - Libras, is known as the language of the deaf, it is not only gestures and mimics, but it is a systematic combination of gestures and mimics plus facial expression and body movements, which enables perfect communication of deaf with other deaf and deaf with listeners who understand the language. Bilingualism is an educational proposal for the Surdo, where it makes it possible to study and communicate with two different languages, Libras and the Portuguese Language. Several Laws, Decrees and Resolutions have been elaborated and disseminated with the intention of including people with disabilities in Brazil, it is then up to the states and municipalities to execute what was said in the legal texts, in order to provide a greater effective participation of these people in society and preparation for the work market.
\end{abstract}

Keywords: Deaf. Laws. Libras. Bilingualism.

\footnotetext{
${ }^{1}$ Especialista em Biologia Geral, Mestrando em Ciências da Educação, graduado em Ciências Biológicas. Professor na rede municipal de ensino na cidade de Araripina-PE. Email: edjonassilvana@gmail.com

${ }^{2}$ Especialista em Geografia Geral, Mestranda em Ciências da Educação, graduada em Geografia. Professora na rede municipal de ensino na cidade de Araripina. Email: francisousa87@gmail.com

${ }^{3}$ Graduação em Fisioterapia pela Faculdade Leão Sampaio. E-mail: anny_carol_15@ hotmail.com

${ }^{4}$ Doutora em Psicologia Social e Pós-doutorado em Ciências da Saúde. Professora Associada da Universidade Federal do Cariri - UFCA.

E-mail: gislenefarias@gmail.com.
} 
Id on Line Revista Multidisciplinar e de Psicologia

Id on Line Multidisciplinary and Psycology Journal

\section{Introdução}

A luta das pessoas com deficiência para ser aceito e respeitado como ser humano normal não é e nunca foi fácil, durante muito tempo essas pessoas ficaram a mercê da sociedade excludente e preconceituosa.

Os primeiros atendimentos às pessoas com deficiências no Brasil, em regime de internato, se deram ainda na época de imperador D. Pedro II, quando este decretou a fundação do Instituto de Meninos Cegos (1854) e o Instituto Benjamim Constant (1857), o segundo passou a ser chamado posteriormente de Instituto Nacional da Educação dos Surdos - INES.

A Lei de Diretrizes e Bases da Educação Nacional de 1961 faz referência a Educação dos Excepcionais (como eram conhecidos) de maneira a garantir a estes o direito à educação das pessoas deficientes. No artigo 89, o governo se comprometeu ajudar as organizações não governamentais que prestasse serviços educacionais às pessoas com deficiências.

A nova LDB, Lei de n9.396/96 traz no seu artigo segundo que a educação é um dever da família e do estado, inspirada nos princípios de liberdade e solidariedade, tendo por "finalidade o pleno desenvolvimento do educando, seu preparo para o exercício da cidadania e sua qualificação para o trabalho" (LDB, 1996). Nesse sentido, família e escola são parceiras, uma depende da outra para ajudar o aluno deficiente ou sem deficiência rumo a sua autonomia e independência, dentro de suas limitações.

A ideia de escola inclusiva busca exatamente isso, incorporar/incluir na rede regular de ensino as pessoas com deficiências, seguindo assim uma orientação de entidade como o Unicef, a Unesco, o Banco Mundial dentre outros, que tem se posicionado a favor que as crianças sejam educadas umas com as outras, independente das suas condições físicas, intelectuais, afetivas, sociais e linguística, tendo em vista que a inclusão é benéfica para todos os envolvidos.

\section{A História da Educação Especial}

A História nos conta que os primeiros atendimentos voltados a pessoas com surdos e cegos aconteceram no Rio de Janeiro, no século XIX com a fundação de duas instituições: o 
Id on Line Revista Multidisciplinar e de Psicologia

Id on Line Multidisciplinary and Psycology Journal

Imperial Instituto Benjamim Constant - IBC, e o Instituto dos Surdos Mudos, em 1857, hoje nomeado de Instituto Nacional de Educação dos Surdos - INES.

As escolas dos surdos e dos cegos foram criadas, isso é fato, mas o ensino aos deficientes era lento, o processo dependia do apoio da sociedade, a qual no momento preocupava-se com seus próprios problemas, com exigências do regime imperial.

De início, esses institutos ofereciam apenas abrigo e proteção como forma de internato. De 1900 a 1950, um mapeamento feito no Brasil, destacou que existia quarenta ambientes ou estabelecimentos públicos de ensino regular que ofertava algum tipo de assistência a alunos com deficiência mental e somente quatorze atendia a pessoas com outras deficiências (MOURA, p.2.2006). Enquanto no cenário mundial já se discutiam a respeito da qualidade e objetivos dos serviços educacionais especiais institucionalizados, o Brasil acontecia uma grande expansão das classes especiais, tanto em escolas públicas como escolas especiais comunitárias (Dechichi, Silva, p.43.2012)

Os alunos surdos e os cegos aprendiam nas aulas a fazer trabalhos manuais, os quais eram vendidos posteriormente para tirar o sustento de suas necessidades básicas, como alimentação e higiene. Os surdos se comunicavam com gestos que criavam, mediante as suas necessidades diárias. Muitas foram às lutas enfrentadas por essas pessoas nessa época e os pais sofriam juntos, pois o maior desejo de um pai e uma mãe é ver seus filhos bem, felizes e saudáveis.

A história relata que somente em 1900 que começa a serem criadas as primeiras classes especiais, onde as crianças deficientes podiam receber um atendimento educacional voltado para leitura e escrita, especialmente no EUA e no Canadá.

Quanto ao atendimento de pessoas com deficiência mental é fundado no inicio do século XX o Instituto Pestalozzi (1926). Já em 1954, foi fundada a primeira Associação de Pais e Amigos dos Excepcionais - APAE; e no ano de 1945, foi criado então o atendimento educacional especializado ás pessoas com superdotação. Esse atendimento acontecia na Sociedade Pestalozzi, por Helena Antipofte.

A expansão do atendimento em relação educação especial, no Brasil, iniciou-se após 1954. Entretanto, esse atendimento somente seria explicitamente assumido pelo governo federal a partir de 1957, quando o ministério da educação começou a prestar assistência técnica e financeira às secretarias de educação e instituições especializadas, promovendo campanhas nacionais para a educação de pessoas portadoras de deficiências (Mendes, 1995, apud Dechichi, Silva, p. 43, 2012) 
Mediante citação acima o governo demorou muito a tomar partido da situação, somente em 1957 que foi dispensar uma assistência técnica e financeira para a causa dos deficientes, o que pôde promover as futuras campanhas de educação a essa classe social grandemente excluída do convício social.

A primeira campanha denominada de Campanha Para a Educação dos Surdos Brasileiros (1957) foi destinada ao atendimento das pessoas com deficiências auditivas. Essa campanha foi instalada no Instituto Nacional de Educação de Surdos -INES, no Rio de Janeiro e sua finalidade era promover medidas necessárias à educação e assistência, de forma ampla, a todos os surdos no território Nacional (ROCHA, 1997). Essa primeira campanha de Educação de Surdos, ocorreu sob a direção de Ana Rimoli de Faria Doria, a qual era também diretora do INES.

Em 1958 nasce a Campanha Nacional de Educação e Reabilitação de Pessoa com Deficiências da Visão. E somente em 1960, influenciada por movimentos liderados pela Sociedade Pestalozzi e pela Associação de Pais e Amigos dos Excepcionais foi que surgiu mais uma campanha, a Campanha Nacional de Educação e Reabilitação de Pessoa com Deficiência - CADEME (MAZZOTTA, 1996).

Segundo o MEC (2010) sobre o processo histórico na luta pela educação dos deficientes, diz o seguinte:

Em 1961, o atendimento educacional às pessoas com deficiência passa a ser fundamentado pelas disposições da Lei de Diretrizes e Bases da Educação Nacional LDBN, Lei $\mathrm{n}^{\circ} 4.024 / 61$, que aponta o direito dos "excepcionais" à educação, preferencialmente dentro do sistema geral de ensino.

Durante os anos 60, surgiam várias iniciativas na área da educação especial, porque a sociedade mostrava interesse em ajudar ou resolver o problema da deficiência. Nesse período, conforme Jannuzzi (1992) “ocorreu uma grande evolução provavelmente a maior, em número de ensino especial a deficiente no Brasil". "Em 1969, existiam 800 estabelecimentos de ensino especial para pessoa com deficiência no país cerca de quatro vezes a quantidade existente em 1960” (DECHICHI, SILVA, 2012, p.43).

A história da educação especial conta que nos anos de 1960 a 1970, o governo esquivando-se de suas responsabilidades, tratou logo de transferir a educação dos deficientes para as ONGs, tendo em vista o vasto crescimento das instituições filantrópicas no país. 
Em 1971, com a Lei no 5.692/71 vem alterando a LDBN de 1961, ao definir "tratamento especial" para os alunos com deficiências físicas, mentais, os que se encontram em atraso considerável que à idade regular de matrícula e os superdotados, porém não foi capaz de promover um sistema eficaz quanto ao atendimento às necessidades educacionais especiais e por cima reforçou o encaminhamento dos alunos deficientes para as classes e escolas especiais, continuando assim uma espécie de segregação, isolamento da sociedade.

As mudanças na nova LDB de 1971 apresentavam avanços consideráveis comparando a lei de 1961. No seu artigo $9^{\circ}$ estava explícito o "tratamento especial aos excepcionais", enfatizando o enfoque terapêutico das ações educacionais, o qual diz o seguinte:

Art. $9^{\circ}$ - Os alunos que apresentam deficiências físicas ou mentais, os que se encontram em atraso considerável quanto à idade regular de matrícula e os superdotados deverão receber tratamento especial, de acordo com as normas fixadas pelos competentes Conselhos de Educação".

Segundo Carvalho (1997) esse artigo promoveu muitas polêmicas sobre a sua interpretação. O problema estava a se referir aos alunos especiais, o texto inclui na mesma categoria alunos com atraso quanto à idade/série. Diante disso as tensões e discussões foram enormes, pois o texto, ao ser interpretado ao pé da letra coloca o aluno apenas com atraso em idade/série como sendo também deficiente sem de fato possuir alguma deficiência. $\mathrm{O}$ atraso de idade/série pode ocorre por diversos fatores, e não necessariamente implica dizer que o aluno é deficiente.

No ano de 1973, o MEC criou o Centro Nacional de Educação - CENES, um órgão ligado ao Ministério da Educação e Cultura, que por sua vez ficou responsável pela gerência da educação especial no país, sob uma visão integracionista, a qual veio a influenciar diversas ações educacionais voltadas a inclusão dos deficientes da época.

Somente em 1978, pela primeira vez, uma emenda na Constituição Brasileira trata do direito da pessoa deficiente. $\mathrm{Na}$ emenda é assegurado as pessoas deficientes a melhoria de sua condição social e econômica, vinculado diretamente a educação especial e gratuita.

A partir da década de 80 , no contexto mundial, a prática de integração social teve seu maior impulso, reflexo dos movimentos de luta e defesa dos direitos das pessoas portadoras de deficiência. As novas conquistas alcançadas por esses movimentos levariam, ao final dessa década, a um questionamento e discussão sobre as ideias envolvidas na prática da integração social e sobre os objetivos com esse processo. A integração social das pessoas com deficiências, da forma como vinha sendo praticada, revelara-se um processo insuficiente para acabar com a discriminação social sofrida por 
Id on Line Revista Multidisciplinar e de Psicologia

Id on Line Multidisciplinary and Psycology Journal

esse grupo de indivíduos. Era necessário propiciar-lhes uma verdadeira participação social, com a garantia de igualdades, oportunidades e direitos. (DECHICHI, SILVA, 2012, p. 45)

A integração social das pessoas com deficiência era uma necessidade de urgência, visando o fim da discriminação social sofrida por essas pessoas. Apesar das políticas públicas, das emendas e leis até o momento, o país não tinha condições de dizer que os deficientes tinham seus direitos garantidos, que o país vivia num regime de igualdade, de participação coletiva, estava bem distante do esperado.

Pensando na melhoria da vida social e econômica da pessoa com deficiência, no ano de 1981 foi o ano Internacional das Pessoas Deficientes, onde nasceu o conceito de uma sociedade para todos, pautado na participação e na igualdade. Dez anos depois, em 1991 a Resolução 45/91 da Organização das Nações Unidas - ONU, propõe uma Sociedade para todos e põe o ano de 2010 como o tempo limite para que as mudanças ocorram. Conforme o documento citado, para esse fim, era necessário haver aceitação das diferenças, individuais; valorização da diversidade humana; destaque e importância do pertencer, do conviver, da cooperação, da contribuição que gerarão vidas comunitárias mais justas (FELIPE, 2006).

O Programa Mundial de Ações Relativas às Pessoas com Deficiência, propôs no ano de 1992 uma mudança a sociedade de maneira que essa minoria tenha seus direitos respeitados, que suas vidas possam ser melhoradas.

Reforçando os movimentos e lutas anteriores quanto à integração da pessoa com deficiência, a Constituição Federal traz como um dos objetivos fundamentais, "promover o bem de todos, sem qualquer discriminação de origem, raça, cor, sexo, idade e qualquer outra forma de discriminação" (art. $3^{\circ}$ - inciso IV). Ainda na mesma lei, no seu artigo 208, vem a definir "como dever do estado, a oferta da educação especial, de preferência na rede regular de ensino".

Dois anos mais tarde, o Estatuto da Criança e do Adolescente - ECA, Lei nº 8.069/90, no artigo 55, vem a reforçar os dispositivos legais supracitados ao determinar que "os pais ou responsáveis tem a obrigação de matricular seus filhos ou pupilos na rede regular de ensino". (MEC, 2010)

Ainda no ano de 1990 surge a Declaração Mundial de Educação para Todos e em 1994 a Declaração de Salamanca, as duas passam então a influenciar a formação das políticas públicas da educação inclusiva. A Declaração de Salamanca veio reafirmando o direito fundamental à educação para todas as crianças e com as necessidades educacionais especiais, 
evitando, sobretudo atitudes discriminatórias, a ponto de criar uma sociedade inclusiva e educada. As crianças com necessidades educacionais especiais deveriam ter acesso à escola regular, onde a escola pudesse usar uma pedagogia centrada nela, no aluno, de maneira a satisfazer suas necessidades. Essa declaração dizia ainda que a escola que possuía uma orientação inclusiva tinha em suas mãos o meio mais eficaz para combater possíveis discriminações, de qualquer natureza e assim podia contribuir na promoção de uma educação afetiva e todos os envolvidos saiam ganhando com essa postura da instituição.

Em 1994, é publicada a Política Nacional de Educação Especial, a qual numa perspectiva de Educação Inclusiva tem como objetivos o "acesso, a participação e a aprendizagem dos alunos com deficiências, transtornos globais de desenvolvimento e altas habilidades/superdotação nas escolas regulares" (MEC, p.19.2010). A aceitação dada aos sistemas de ensino foi para promover uma educação de respostas às necessidades educacionais especiais, de maneira a garantir (Ibid., p.19):

Transversalidade da educação especial desde a educação infantil até a educação superior; Atendimento educacional especializado; Continuidade da escolarização nos níveis mais elevados do ensino; Formação de professores para o atendimento educacional especializado e demais profissionais da educação para a inclusão escolar; Participação da família e da comunidade; Acessibilidade urbanística, arquitetônica, nos mobiliários e equipamentos, nos transportes, na comunicação e informação; e Articulação intersetorial na implementação das políticas públicas.

Os objetivos da Política Nacional de Educação Especial são bem amplos, envolvem todos da educação e diversos temas. A começar pela atenção que deve ser dada desde a educação infantil até ao ensino superior; bem como a continuidade a escolarização a níveis mais elevados do sistema de ensino no país, visando uma melhor formação pessoal e profissional do aluno, para cumprimento da LDB quando diz que a escola "tem por finalidade o pleno desenvolvimento do educado, seu preparo para o exercício da cidadania e sua qualificação para o trabalho" (art. $2^{\circ}$ ); o atendimento educacional especializado- AEE, uma novidade para a inclusão e que realizado de forma correta trás resultados incríveis na vida do aluno com deficiência. A formação de professores que merece atenção redobrada, tendo em vista a necessidade de uma melhor qualificação para os realmente tem contado direto e diário com o aluno. 
Id on Line Revista Multidisciplinar e de Psicologia

Id on Line Multidisciplinary and Psycology Journal

A participação da família é indiscutível em todos os sistemas de ensino, sem ela as coisas não andam, o processo não evolui, por isso, escola e família se completam e precisam comungar com os mesmo objetivos educacionais.

A acessibilidade urbanística é outro assunto de extrema importância, passa pela construção de rampas em todos os estabelecimentos urbanos antigos e projetos novos já dentro das normas. Aqui se a mudanças necessárias em mobiliários, adaptação de transportes, nos meios de comunicação em geral.

Em 1990, o decreto 3298/99 que reformula a Lei 7853/89, define a educação especial como uma modalidade transversal a todas as modalidades de ensino.

Em 1999, foi promulgado no Brasil pelo Decreto $n^{\circ}$ 3.956/2001 a Convenção da Guatemala que veio afirmar que as pessoas com deficiências têm os mesmo direitos humanos e liberdades fundamentais igual as demais pessoas. Repudiando definitivamente qualquer tipo de discriminação quanto aos deficientes, qualquer ato que impeça ou anule o exercício dos direitos humanos garantindo por lei.

Já no ano de 2001, a CNE/CEB, no seu artigo $2^{\circ}$, acompanhando o processo de mudança publica o seguinte:

Os sistemas de ensino devem matricular todos os alunos, cabendo às escolas organizarem-se para o atendimento aos educandos com necessidades educacionais especiais, assegurando as condições necessárias para uma educação de qualidade para todos. (MEC/SEEP, 2001).

No ano seguinte a Lei 10436/02 reconhece a língua de sinais como meio legal de comunicação e expressão para a comunidade surda.

Em 2003, o MEC implementou o Programa de Educação Inclusiva com direito a diversidade, visando o apoiar uma transformação dos sistemas de ensino inclusivos, no qual professores e gestores dos municípios de todo o país sejam submetidos a uma ampla formação, no intuito de garantir o direito de acesso de todos os deficientes a escola, bem como à oferta do atendimento educacional especializado e a garantia da acessibilidade.

Dois anos mais tarde, o Decreto de $n^{\circ} 5.626 / 05$ regulamenta a Lei ${ }^{\circ} 10.436 / 2002$, onde reafirma a garantia do acesso à escola para o aluno surdo, pondo a Libras como disciplina curricular, e visa ainda à formação de professor, instrutor e tradutor/intérprete de Libras. A Língua Portuguesa é posta como segunda língua para os alunos e propõe uma educação bilíngue. 
Id on Line Revista Multidisciplinar e de Psicologia

Id on Line Multidisciplinary and Psycology Journal

No ano de 2007, é lançado o Plano de Desenvolvimento da Educação - PDE, onde seu eixo de destaque é o seguinte:

(...) formação de professores para a educação especial, a implantação de salas de recursos multifuncionais, a acessibilidade arquitetônica dos prédios escolares, acesso e a permanência das pessoas com deficiência na educação superior e o monitoramento do acesso à escola dos favorecidos pelo Benefício de Prestação Continuada-BPC. (MEC, 2010, p.15).

Nesse sentido pensar na formação do professor, desde sua formação inicial, seja no ensino médio ou superior, é crucial um currículo voltado para educação especial. Além disso, se faz necessária formação contínua, sempre atualizada e prática, de maneira a refletir nos pontos positivos e melhorar os negativos. Não dar para esquecer o docente da sala de recursos multifuncionais, que precisa passar pelas mesmas formações que o professor da sala regular de ensino, no intuito de um plano comum entre as duas práticas.

A acessibilidade arquitetônica dos prédios escolares é algo previsto em lei e tem sido feito nas escolas de arquitetura antiga, pois os novos projetos já nascem com as exigências necessárias, porém, mudanças na parte física somente não são sinônimo real de inclusão. A primeira mudança deve ser de mentalidade das pessoas de forma geral, atentando para sentimento de igualdade e aceitação da diversidade.

O Benefício da Prestação Continuada da Lei Orgânica da Assistência Social (BPC/LOAS) é a garantia de um salário mínimo mensal ao idoso acima de 65 anos ou ao cidadão com deficiência física, mental, intelectual ou sensorial de longo prazo, que esteja fora de condições de participar de forma plena e efetiva na sociedade, em igualdade de condições com as demais pessoas. Porém, para se enquadrar na classe que tem direito, é necessário que a renda por pessoa do grupo familiar seja menor que 1/4 do salário-mínimo vigente. Cabe destacar que esse benefício não paga $13^{\circ}$ salário e não deixa pensão por morte. (Previdência Social, 2016)

\section{A chegada da criança Surda na Família}

Inicialmente quando uma mulher decide ter um filho, ela pensa no seu bebê de forma perfeita, sem máculas ou deficiências. Esse é o natural das coisas, dos seres humanos. No entanto, quando o bebê nasce surdo, os pais sofrem um pouco com o susto da notícia, a família 
Id on Line Revista Multidisciplinar e de Psicologia

Id on Line Multidisciplinary and Psycology Journal

libera um sentimento de piedade, mas isso é passageiro, em pouco tempo todos retomarão a alegria com a chegada de mais um membro na família.

Depois do susto da condição da surdez dada pelo médico, os pais recorrem à medicina a tentativa de reverter ou pelo menos amenizar a situação. A atitude dos pais não significa que não estão felizes com o filho surdo, mas que compreendem as inúmeras dificuldades a serem enfrentadas por ele em todas as etapas da sua vida.

Infelizmente essa é a prova da nossa cultura preconceituosa, discriminatória e seletiva. A princípio "os pais ficam "perdidos" diante da constatação de um filho surdo. A tendência é procurar um médico e buscar a cura de seu filho" (SILVA, REIS, p.107, 2010). Qualquer ser humano ficaria um tanto preocupado ou com atenção redobrada por ter um filho deficiente, pois as deficiências, seja ela qual for, não é o natural do biótipo do homem, por isso se justifica que os pais queiram encontrar a "cura" para seu filho.

Com o passar dos dias, adquirindo conhecimento acerca desse novo universo, das possibilidades existentes para os surdos, da educação possível, os pais começam adentar no processo de aceitação, visando antes de tudo à felicidade da criança, o seu bem estar, e para isso pais que amam não medem esforços pelos filhos, seja ele deficientes ou não.

\section{Origem e atuação do Instituto Nacional de Educação de Surdos - INES}

O Instituto Nacional de Educação de Surdos - INES, foi criado em 1856 na época do Brasil Império de D. Pedro II, tendo como idealista o professor francês Ernest Huet, surdo e exdiretor do Instituto de Surdos-Mudos de Bourges, comuna francesa.

A princípio o instituto era um asilo, onde somente os surdos do sexo masculino eram aceitos, os quais vinham de todos os lugares do país, outros foram vítimas do abandono pelas famílias. Somente em 1931, foi fundado o externato feminino pautado em oficinas de costura e bordado.

O ensino profissionalizante oferecido no INES estava voltado às técnicas agrícolas, tendo em vista que a maioria dos surdos eram oriundos de famílias de pobres do meio rural (CARMO, 2005) A partir da década de 1870, foram inseridas outras oficinas profissionalizantes, por exemplo, de encadernação e sapataria. Com o passar dos anos outras 
Id on Line Revista Multidisciplinar e de Psicologia

Id on Line Multidisciplinary and Psycology Journal

atividades também passaram a fazer parte da rotina dos alunos do instituto, bem como alfaiataria, desenho, marcenaria, ensino industrial, datilografia e modeladas, além da já existente anteriormente (MATTOS, 2002)

No ano de 1911 o INES decidiu pelo oralismo como método de educação dos surdos, influenciado pela tendência no congresso de Milão (1880), onde o oralistas apresentaram diversos surdos que falavam bem e na assembleia de enceramento realizaram uma votação e a maioria dos europeus e ouvintes optaram pela "aprovação do uso exclusivo e absoluto da metodologia oralista, proibindo, a partir de então, a utilização da linguagem de sinais" (GUIMARÃES, BORBA, p.51, 2009).

Durante quase um século o oralismo foi amplamente divulgado e implantado, sem nenhum questionamento sobre sua eficácia educacional na prática. Essa abordagem pautada na oralidade não mostrou bons resultados, já que "os surdos profundos, em sua maioria não conseguiam desenvolver uma linguagem oral que lhe permitisse conviver em sociedade e apresentavam muitas dificuldades para aprender a ler e escrever" (Ibid., 2009).

Atualmente o INES trabalha numa abordagem por meio do bilinguismo, que visa instruir o surdo para a utilização de duas línguas no cotidiano escolar e na sua rotina social. As duas línguas são: a primeira a ser dominada é a língua de sinais - Libras, e a segunda a ser estudada é língua da comunidade ouvinte, no caso, a Língua Portuguesa.

\section{O Feneis}

Federação Nacional de Educação e Integração dos Surdos foi criada em 1987, conhecido a início como Feneida e era composta apenas por pessoas ouvintes. Tempos depois passa a ser conhecimento pelo nome de Feneis.

O maior objetivo dessa entidade é a divulgação da Língua é a divulgação da Língua Brasileira de Sinais - Libras, através de várias atividades, como seminários, cursos, encontros e outros. É uma entidade filantrópica, sem fins lucrativos, que nasceu para lutar pelos direitos de igualdade e participação dos jovens surdos, negros surdos, surdocegos no contexto social. A entidade realiza trabalhos na área de educação, cultura, saúde e assistência social, todos voltados para os Surdos e suas particularidades. 
Id on Line Revista Multidisciplinar e de Psicologia

Id on Line Multidisciplinary and Psycology Journal

Os programas do Feneis são todos educacionais, sendo informal e permanente, com vista na valorização da pessoa como ser humano, estimulando o surdo para o desenvolvimento da sua autonomia pessoal, a interação e o contato com expressões e modos diversos de pensar, agir e sentir (Wikipédia). O feneis é filiada a Federação Mundial dos Surdos, e tem contribuído amplamente na inserção do surdo no mercado de trabalho.

\section{O Bilinguismo na educação dos surdos}

No tocante a educação bilíngue, a lei portuguesa, no decreto lei 3/2008, de 7de janeiro, no seu artigo $23^{\circ}$, diz dessa maneira:

A educação das crianças e jovens Surdos deve ser feita em ambientes bilíngues, que possibilitem o domínio da LGP, o domínio do português escrito e, eventualmente, falado, competindo á escola contribuir para o crescimento linguístico dos alunos Surdos, para a adequação do processo de acesso ao currículo e para a inclusão escolar e social.

O bilinguismo não deve ser encarado com uma obrigação ou necessidade das pessoas surda, mas sim, como um direito, tendo como base a premissa de que as línguas gestuais são consideradas patrimônio da humanidade e por fim, expressam de forma eficiente a cultura da comunidade surda.

A abordagem bilíngue é mais acessível no processo educacional de surdos, pois a mesma além de respeitar e incentivar o estudo da língua materna, pode construir um ambiente propício para o seu desenvolvimento escolar, por meio da língua de sinais.

Nessa direção, Quadros diz o seguinte: “Quando me refiro ao bilinguismo, não estou estabelecendo uma dicotomia, mas sim reconhecendo as línguas envolvidas no cotidiano dos surdos, ou seja, a Língua Brasileira de Sinais e o Português no contexto mais comum do Brasil." (2000, p.54).

Essa proposta educacional começou a estruturar a partir do Decreto $\mathrm{n}^{\circ} 5.626$, de 22 de Dezembro de 2005, que regulamenta a lei sobre a Língua Brasileira de Sinais -Libras, conforme mencionada anteriormente, e que dá outras providencias. No seu artigo $1^{\circ}$, “é reconhecido como meio legal de comunicação e expressão a Língua Brasileira de Sinais - Libras”, a mesma passa a ser inserida como disciplina curricular obrigatória nos cursos de formação de professores para 
Id on Line Revista Multidisciplinar e de Psicologia

Id on Line Multidisciplinary and Psycology Journal

o exercício do magistério, em nível médio e superior, bem como nos cursos de fonoaudiologia, públicos ou privados, sendo o ensino municipal, estadual ou federal. (Ibid., art. $3^{\circ}, 2005$ ).

A proposta bilíngue possibilita ainda que o aluno surdo faça uso de duas línguas, podendo ele escolher em cada situação do seu cotiando a que mais lhe favorece a comunicação na comunidade dos surdos ou dos ouvintes.

Na prática o bilinguismo veios a somar na vida estudantil do aluno surdo, pois além de facilitar o desenvolvimento cognitivo do mesmo proporciona uma ampliação do vocabulário. O ideal é que a principio o aluno surdo domine a língua de sinais e posteriormente volte-se para o estudo da segunda língua, a Língua Portuguesa, tendo em vista que a o aprendiz utiliza a primeira língua para aprender à segunda.

\section{A Língua Brasileira de Sinais}

A Libras - Língua Brasileira de Sinais é uma língua utilizada pelos Surdos no Brasil, ela é visual e gestual, distinta dos outros idiomas do mundo que são orais e auditivos.

Somente em 2002, como vimos anteriormente a Libras foi reconhecida diante da lei como um meio de comunicação oficial das comunidades surdas no Brasil. Hoje ela é obrigatória como disciplina nos cursos de formação de professores para o exercício do magistério em nível médio (curso Normal) e superior (Pedagogia, Educação Especial, Fonoaudiologia e Letras). Apesar do que diz a lei muitos surdos ainda sentem inúmeras dificuldades de serem inseridos no contexto social e no mercado de trabalho.

É verdade que a lei existe, mas ela ainda não é praticada na sua essência e de maneira correta, existem muitas escolas, hospitais, consultórios, ambientes públicos que não possuem uma infraestrutura adequada e nem profissionais qualificados para atendem os surdos quando necessário. 
Id on Line Revista Multidisciplinar e de Psicologia

Id on Line Multidisciplinary and Psycology Journal

\section{Atendimento Educacional Especializado - AEE}

O Atendimento Educacional Especializado -AEE, previsto na Politica Nacional de Educação Especial na Perspectiva da Educação Inclusiva (2008) é um serviço que: “(...) identifica, elabora e organiza recursos pedagógicos e de acessibilidade, que eliminam as barreiras para a plena participação dos alunos, considerando suas necessidades específicas" (MEC/2010).

Esse atendimento não substitui o ensino regular, mas surge para complementar ou suplementar a formação, visando desenvolver a autonomia e independência na escola e no contexto social do aluno com deficiência.

O MEC (2010) referindo-se ao AEE, se posiciona da seguinte maneira:

Dentre as atividades de atendimento educacional especializado são disponibilizados programas de enriquecimento curricular, o ensino de linguagens e códigos específicos de comunicação e sinalização e tecnologia assistiva. Ao logo de todo o processo de escolarização esse atendimento deve estar articulado com a proposta pedagógica do ensino comum. $\mathrm{O}$ atendimento educacional especializado é acompanhado por meio de instrumentos que possibilitem monitoramento e avaliação da oferta realizada nas escolas da rede pública e nos centros de atendimento educacional especializados públicos ou conveniados.

Nessa direção, fica claro que o atendimento educacional especializado anda em comunhão com o ensino regular de ensino, tendo em vista que o profissional do atendimento no aee possui em harmonia curricular com o profissional do ensino regular. Esse atendimento deve acontece no contra turno do horário de aula do aluno com deficiência. Os profissionais devem manter atualizado sempre uma auto avaliação do seu trabalho, na busca de melhorar-se a cada atendimento, visando contribui positivamente no desempenho do aluno atendido.

Ao contrário de que muitos pensam, esse atendimento não tem a função de escolarizar, mas de oferecer condições complementares ao desenvolvimento da pessoa para que ela consiga se desenvolver bem na escola. Portanto, no AEE não se oferece aulas de reforço aos alunos; na realidade o que oferece é a instrumentalização desses alunos para que não precisem desse tipo de recurso (SILVA, REIS, 2012, p.119)

O referido atendimento deve está presente a partir da Educação Infantil, por meio do lúdico, de diversas formas de comunicação e estímulos nos aspectos físicos, emocionais, cognitivos, psicomotores e sociais da criança. (op. Cit.2010). 
Esse atendimento para o aluno Surdo deve ser ofertado na modalidade oral e escrito, como também na língua de sinais, no intuito de utilizar todos os recursos disponíveis a favor dessa pessoa. $\mathrm{O}$ aluno surdo deve ser matriculado em turma do ensino regular, para que ele possa conviver com situações diversas do uso da linguagem oral e escrita, porém é interessante que o docente dessa turma conheça a língua de sinais e, preferencialmente que disponha de um intérprete em sua sala.

\section{Considerações Finais}

Diante da história de lutas em prol dos Surdos, com Leis e Decretos diversos fica evidente que essa parcela da população tem conquistado o respeito e espaço perante a sociedade. Entretanto, não basta que haja leis e decretos determinando os direitos dos surdos, é necessário que tudo que foi declarado seja cumprido, posto em prática. A luta dos surdos já está super abastecida com teorias que anunciam seus direitos, cabe agora que os estados e municípios coloquem em prática, começando por capacitar os docentes, ofertar as unidades educacionais intérprete e tradutores de Libras para acompanhar diariamente o aluno no contexto escolar.

Essa abordagem bilíngue é de fundamental importância para a aprendizagem da criança surda, contudo os professores devem planejar atividades diversificadas e adaptadas para atender as necessidades dos alunos. A criança ou jovem surdo é potencialmente capaz de desenvolverse igualmente uma pessoa ouvinte, necessita apenas de oportunidades favoráveis e comunicativas dentro de suas necessidades especiais.

É bom lembrar que ter o acesso a escola não significa qualidade de ensino. O que ocorre é isso, a "inclusão" atual se dar pelo simples fato do aluno surdo ou com qualquer outra deficiência está frequentando uma escola, mais a dinâmica das aulas estão voltadas diretamente para os ouvintes ou sem deficiência, estes que adaptam a escola e na verdade a escola que precisa se adaptar ao aluno.

Faz necessário que as políticas públicas educacionais oferecem condições de acesso à sociedade, por meio oficiais ou privados, para ter conhecimento da língua de sinais, bem como os direitos adquiridos pelos Surdos. 
Id on Line Revista Multidisciplinar e de Psicologia

Id on Line Multidisciplinary and Psycology Journal

O reconhecimento da Língua Brasileira de Sinais, oficialmente como língua é uma grande conquista para os Surdos, um meio caminho andado para aquisição da Língua Portuguesa e condição básica para o exercício da cidadania.

\section{Referências}

BRASIL. Ministério da Educação. Secretária de Educação Especial. Marcos Políticos-legais da Educação Especial na Perspectiva da Educação Inclusiva/ Secretaria de Educação Especial, -2010. 72p. Brasília.

BRASIL. LDB - Lei de Diretrizes e Bases da Educação Nacional. 11ª edição. Câmara dos Deputados. Brasília/2015.

DECHICHI, C. SILVA, L.C.da. FERREIRA, J. M.( Organizadoras) CURSO BÁSICO: educação especial educacional e atendimento educacional especializado. Série: Material Didáttico v.1. Uberlândia: EDUF, 2012.

DECLARAÇÃO DE SALAMANCA. Espanha, 1994.

FELIPE, T. Políticas para Inserção da Libras na Educação de Surdos. Em Contexto. Libras Artigo Publicado pela Revista Informativ - Científico Espaço, INES - Rio de Janeiro. N. 25/26, pp 33-47; janeiro-dezembro/2006.

GUIMARÃES, G. BORBA, R. Reflexões sobre o ensino de Matemática nos anos iniciais de escolarização. Recife: SBEM, 2009.

JANNUZZI, G. A luta pela educação da pessoa com deficiência mental no Brasil. Campinas/SP: Editores Associados, 1992.

QUADROS, R.M. de. Alfabetização e o ensino da língua de sinais. Textura, Canoas n3 p. 54, 2000.

MAZZOTA, M. J.S. Educação Especial no Brasil: História e Políticas. São Paulo: Cortez, 1996.

MATTOS, L.C. Educação e Surdez: Por uma Melhor Qualidade de Vida. (UERJ), 2002.

MOURA, C. P. R. de. Educação Inclusiva: Desafios e Perspectivas. Revista Educare/ ISEIB - Montes Claros -MG. V. 2/2006.

ROCHA, S. Histórico do INES. Espaço - Informativo Técnico - Científico [do] INES. Edição comemorativa, 140 anos. Belo Horizonte: Líttera, 1997. 
SILVA, K.M.de S.C. SILVA, L. C. da Silva. REIS, F. CURSO BÁSICO: Educação especial educacional e atendimento educacional especializado. Série: Material Didáttico v.1. Uberlândia: EDUF, 2012.

Sites:

LEGISLAÇÃO DE LIBRAS. http://www.libras.org.br//leilibras.php

CARMO, S. M. do. http://www.manancialvox.com/diversos/Sonia-do-Carmo-A-historia-daeducacao-especial.txt.(2005) Acesso em 01/08/2016.

PREVIDÊNCA SOCIAL: http://www.previdencia.gov.br/servicos-ao-cidadao/todos-osservicos/beneficio-assistencial-bpc-loas/Publicado: 01/09/2015 18:06 Última modificação: 30/06/2016 17:23

\section{Como citar este artigo (Formato ABNT):}

LOPES, E.S.; SILVANA, F.S.; VIEIRA, A.C.C.; OLIVEIRA, G.F. Políticas Públicas e Organizações na Educação do Surdo. Id on Line Revista Multidisciplinar e de Psicologia, Nov-Dez. de 2016, vol.10, n.32, p. 228-244. ISSN: 1981-1179.

Recebido: $29 / 08 / 2016$

Aceito: 17/09/2016 